\title{
Dual role of complement in tumour growth and metastasis (Review)
}

\author{
CORDULA STOVER \\ Department of Infection, Immunity and Inflammation, University of Leicester, University Road, Leicester LE1 9HN, UK
}

Received September 29, 2009; Accepted November 13, 2009

DOI: 10.3892/ijmm_00000346

\begin{abstract}
Complement-dependent cytotoxicity is one of the mechanisms by which therapeutic monoclonal antibodies are successful against cancer. Complement is one of the innate immune defence systems, whose activation products and membrane-bound regulators interact with cells of the adaptive immune response. The complement system is currently undergoing a re-appreciation in its role within the immune surveillance of tumour. The majority of human tumours are low immunogenic. Complement may be involved through direct, 'danger signal'-elicited activation or via infiltration of inflammatory cells, which express complement components. Inflammatory cells may be associated with malignant transformation and tumour regression. The evidence for the effects of complement activation and regulation on tumour progression and expansion will be reviewed using in vivo, in vitro, and patient studies, and conclusions drawn for the implications in therapy and management of tumour patients.
\end{abstract}

\section{Contents}

1. Background

2. Two opposing roles for complement in tumour control

3. Tumour-associated inflammation, determinants and effects

4. Mouse models of tumour growth and metastasis involving complement

5. Complement as targetable modulator in cancer therapy

6. Conclusions and outlook

\section{Background}

Complement is a local and systemic mediator of the first line response to inflammatory or infectious perturbations of the steady state. It is a system of zymogens, which are activated

Correspondence to: Dr Cordula Stover, Department of Infection, Immunity and Inflammation, University of Leicester, University Road, Leicester LE1 9HN, UK

E-mail:cms13@le.ac.uk

Key words: complement, inflammation, tumour immunity in a hierarchical cascade on microbes or altered cells via the classical (antibody mediated), lectin (carbohydrate moiety mediated) or alternative pathway. From the concept of complement being 'a guardian of the extracellular space' (1), it follows that its functional limitation in this compartment relies on fluid phase regulators. Importantly, complement components and regulators are also expressed in lymph nodes and spleen. Complement has emerged as a player in the adaptive humoral and cellular immune responses and has been described as 'nature's premier adjuvant' (1). It exerts this newly appreciated function by tagging antigen and increasing B-cell signalling via CD19/21 or retaining antigen on dendritic cells via CD21 (2), by priming and activating $\mathrm{T}$ cells $(3,4)$, by supporting differentation and maturation of dendritic cells (5), and by aiding immunologic memory (6).

Complement has become an entity to consider in a variety of (non-infectious) conditions such as: autoimmune disease, ischemia reperfusion, and tumour immunology. Evidence in support of a role of complement in the latter is contradictory; while some studies show a role for complement in immune surveillance, others demonstrate a role for complement in promoting tumour growth. These studies will be summarised hereafter.

\section{Two opposing roles for complement in tumour control}

Binding of natural, anti-carbohydrate antibodies (7) or tumour-specific antibodies initiates activation of complement via the classical pathway and effects tumour cell lysis via the membrane attack complex (complement-dependent cytotoxicity). Leukemic cells have been described to efficiently activate both, lectin and alternative pathways of complement, leading to opsonisation and uptake via NK cells and leukocytes (8). Antibody-dependent cellular cytotoxicity is enhanced via C5a-mediated upregulation of Fc $\gamma \mathrm{R}$ (8). In a mammary sarcoma model, C5a has been shown to exert an inhibitory effect on tumour growth (9). Further, binding of complement components $\mathrm{C} 1 \mathrm{q}, \mathrm{MBL}$ and/or properdin contributes to apoptotic clearance (10) (Table I). Homoiostatic removal of apoptotic cells avoids tumour development (11).

Tumour cells are protected from complement attack via membrane bound and soluble/membrane-associated regulators (CD55, termed decay accelerating factor or DAF; CD59, termed protectin; CD46, termed membrane cofactor protein; and factor H). CD55 is particularly well researched; tumourexpressed metalloproteinase MMP-7 releases CD55 from the extracellular matrix (12). In addition to its downregulatory 
Table I. Complement as adjuvant mediator of anti-tumour immune surveillance.

Enhancement of antibody-dependent cellular cytotoxicity

Complement-dependent cytotoxicity

Inhibition of tumour growth

Contribution to apoptotic clearance
Table III. Complement in tumour immuno-editing.

Elimination:

Antitumor activity of IL-12 (IL-12 production - IFN $\gamma$ induced, complement mediated; ref. 24)

Danger signals: Calreticulin exposure and ensuing complement activation (25)

Carbohydrate-directed cytotoxicity of natural IgM antibodies (26)

Equilibrium:

The phenotype of the tumour is the result of an individual interplay of host immunity and tumour.

Escape:

Suppression of T-cells via mast cells (complement-mediated uptake of serotonin; ref. 27)

Procachectic effects via complement-mediated cytokine induction (IL-6)

On the other hand, complement activation is a significant effector mechanism for the success of, e.g., rituximab treatment (30) and is likely to step to the forefront with the development of tetravalent monoclonal antibodies, which exhibit enhanced ability to activate the complement (31). Confounders in the interpretation of the dual nature of the role of complement in tumour growth and metastasis, is the fact that tumours and their stromal tissue harbour a continuum in activated cells in an altered micro-environment; tumour-infiltrating leukocytes may be growth promoting or reducing, opposing effects likely to be a reflection of acute and chronic events, which manifest over time (32). Therefore, knowledge of presence or absence of necrosis, types of tissue, tumour-specific mechanisms (stroma/ malignant cells), integration of time and co-morbidities are needed to achieve a clearer understanding of the specific impact of complement on development and control of tumour. Polymorphisms in innate immune players may be under-appreciated determinants in these processes (33).

\section{Tumour-associated inflammation, determinants and effects}

Tumour begets inflammation and chronic inflammation begets tumour. Lymphocytic infiltration and complement activation in tumour parenchyma appear to control malignancy in papillary thyroid carcinoma because of a significant preponderance of cellular deposits of $\mathrm{IgG}, \mathrm{C} 3 \mathrm{~d}, \mathrm{C} 4 \mathrm{~d}$ and C5 in cancerous tissue compared to non-cancerous tissue (34). Chronic bacterial (H. pylori) or viral (hepatitis $\mathrm{B} / \mathrm{C}$ virus) infection may lead to malignant transformation of host cells. Acute inflammation is a risk factor for cancer progression, while chronic inflammation, involving, apart from complement, a range of other factors such as reactive oxygen species, vascular endothelial cell growth factor (VEGF), matrix 
metalloproteinases, is involved in cancerogenesis (35). Necrosis acts in a proinflammatory way and matures dendritic cells in tumour tissue. In the absence of necrosis, immature dendritic cells predominate (36) and increase T regulatory cells (37).

Complement activation leads to an increase in VEGF (38). VEGF in turn increases synthesis of CD55, which promotes neoangiogenesis via binding to seven-span transmembrane receptor CD97 (12). Neoangiogenesis is co-determined by the interactions of CD36 and TSP1 (39). Thrombospondin has 'properdin-like' type I repeats (40), and properdin appears to have a conserved stretch of amino acids encompassing the CD36 binding motifs of TSP1 (41), but its relation to angiogenesis has not yet been explored. Of note, terminal complement components also harbour thrombospondin modules (C6, C7, C8, C9).

Inflammatory conditions have an impact on the glycosaminoglycan decoration of eukaryotic cells. Binding of negative and positive complement regulators to the surface glycosaminoglycan heparansulfate is a significant determinant of growth and metastasis in mouse melanoma model (42). This binding may occur via histidine-rich glycoprotein, which binds to heparansulfate. Properdin, key protein in amplification of complement activation, has been found to bind to glycosaminoglycan moieties on the cell surface (43 and own unpublished data), but the experimental approach chosen (digestion of heparan sulfate) does not exclude involvement of histidine-rich glycoprotein.

Through its interaction with heparin and its derivatives, complement becomes a player in anticoagulation approaches in the management of cancer patients. A recent meta-analysis has reported a favourable outcome for patients survival in studies using low molecular weight heparin, but more systematic studies are needed to refine patient and cancer groups $(44,45)$. A greater understanding of the contribution made by the interaction of complement with low molecular weight heparin would be useful in this endeavour, as knowledge in this area is fragmented; it is known that low molecular weight heparin binds $\mathrm{C} 1 \mathrm{q}$ and interferes with its assembly to form hemolytically active $\mathrm{C} 1$, the complex of C1q, C1r2, C1s2 (46). Binding of low molecular weight heparin to immobilised $\mathrm{C} 1$ increases the activity of $\mathrm{C} 1$ inhibitor (47). The interference in complement activity could be an additional factor, alongside the anticoagulant activity of low molecular weight heparin, which mediates its significant antimetastatic action. The complement effectors are unknown, but may receive attention as non-anticoagulant heparins are put to use, which successfully inhibit tumour progression $(48,49)$.

Hypoxia downregulates expression of complement inhibitors by tumour cells (not endothelial cells; ref. 50) in vitro (51); downregulation of factor $\mathrm{H}$ and I secretion and of CD46 expression in non-small cell lung cancer cells exposed to hypoxia, is coincident with increased deposition of $\mathrm{C} 3 \mathrm{~b}$ and $\mathrm{C} 9$. These results call into question the conclusion of recent studies in which CD59 (CD59 restricts formation of membrane attack complex) or CD55 (CD55 accelerates decay of convertases) and CD46 (acts as cofactor in factor Imediated cleavage of $\mathrm{C} 3 \mathrm{~b}$ and $\mathrm{C} 4 \mathrm{~b}$ ) were targeted by retrovirus mediated RNAi or antisense-ODNs, respectively and proposed as gene therapy targets, as these cells were grown in normoxia $(52,53)$.
Chronic inflammation induces glycosylation changes in certain serum glycoproteins, which are present also in cancer, and may have functional consequences, favoring anti-apoptotic mechanisms (54). C3 and histidine-rich glycoprotein are affected by this phenomenon and have been characterised as markers of colorectal cancer (55). It is intriguing to speculate that the increased sialylation and fucosylation observed for C3 and histidine-rich glycoprotein convey for these proteins a greater reactivity, affinity or stability.

\section{Mouse models of tumour growth and metastasis involving complement}

Cathepsin, isolated from highly metastatic melanoma, inactivates complement-mediated lysis. After transfection of cells from a non-metastasising melanoma clone, the rate of metastasis is significantly increased and relates to the ability of cathepsin to cleave C3 (56). Similarly, matrix metalloproteinase-1 cleaves complement $\mathrm{C} 3$ and protects tumour cells from injury. Its prometastatic activity is directly related to the ability of matrix metalloproteinase-1 to cleave $\mathrm{C} 3$, as seen from in vivo models using matrix metalloproteinase-1 transfected tumour cells, C3-deficient mice, and their controls (57).

Tumour-associated complement activation may significantly enhance tumour growth by suppressing the antitumour cellular immune response (20). This study, using a subcutaneous cervical carcinoma model and several specific knock out mouse strains, revealed that tumour growth depended on the presence of complement C3, C4, and C5aR. C3 cleavage products and C1q were found associated with tumour vasculature. C5aR blockade led to a greater infiltration of $\mathrm{CD}^{+} \mathrm{T}$-cells and smaller tumours. Enhanced $\mathrm{CD}^{+}$antitumour activity is also observed when Crry, the mouse homologue of CR1 and 2, is downregulated in a mouse model of metastatic bladder cancer. Survival in this model depends on CD8 ${ }^{+}$T-cells and C3 (17). Human tumours, by contrast, generally escape $\mathrm{CD}^{+} \mathrm{T}$-cell mediated elimination due to a loss of MHC I expression.

Silencing of the genes for complement downregulators CD59 and CD55 diminishes the tumour burden in mouse models of ovary and prostate cancer, respectively $(52,58)$. However, instillation of tumour cells transfected with a C5a expressing plasmid leads to tumour regression. The implications are not clear as unmanipulated tumour cells, not control plasmid transfected cells, were used as controls (9). Studies exploring the relevance of complement in tumour immunity are limited (Table IV). Therefore, what is the clinical relevance of complement activation in tumour expansion?

\section{Complement as targetable modulator in cancer therapy.}

TLR-dependent signalling may exert tumour growth-restricting or -promoting effects, which are mediated by a polarisation to either Th1 or Th2, respectively (37). Complement and TLRs are surface pattern recognition systems, and their integration has only recently been explored $(16,59)$. The modulation of their interactions through targeting of complement components has not yet been investigated. So far, the clinical studies focus on evaluating the beneficial effect of complement activation in controlling tumour growth and metastasis: 
Table IV. Complement in mouse models of tumour immunity.

\begin{tabular}{llll}
\hline Gene interference & \multicolumn{1}{c}{ Models } & & \multicolumn{1}{c}{ Effect } \\
\hline C3 KO, C4 KO, C5aR KO & & \\
Crry siRNA & Syngeneic, in vivo & Impaired activation of MDSC, less tumour growth & 20 \\
CD59 siRNA & Syngeneic, in vivo & Enhanced CD8 + anti-tumour activity & 17 \\
CD55 siRNA & Xenografts, in vivo & Less tumour burden (increased lysis) & 52 \\
C5a & Syngeneic, in vivo & Less tumour burden (increased lysis) & 58 \\
& Syngeneic, in vivo & Blocks cell cycle, increases apoptosis, tumour regression & 9 \\
\hline
\end{tabular}

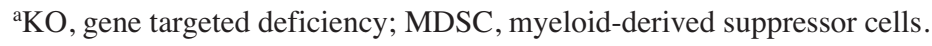

Complement receptor CR3 mediates the beneficial effect of the adjuvant therapy using $\beta$-glucans (60). Concomitant complement activation is beneficial in the success of photodynamic therapy of murine squamous cell carcinoma, where a decrease in the expression of Crry, CD55 and CD59 was noted. This is further enhanced by the adjuvant, intraperitoneal administration of anti-factor $\mathrm{H}$, anti-Crry, anti-CD59 or, by intratumoural instillation, properdin (61). An antibody-mediated blockade of CD59 in vitro (using blood from patients with colorectal carcinoma) was shown to enhance the antigen specific $\mathrm{CD}^{+}{ }^{+} \mathrm{T}$-cell response (62). In fact, the combination of specific, anti-tumour monoclonal antibodies with blockade of membrane bound complement regulators is heralded as a therapeutic concept with promise, especially when bispecific antibodies can be used, which have significantly decreased ability to bind to cells not expressing the tumour antigen (63).

It is possible that the success of the approach to increase complement activation is due to interference with a property conveyed by a complement protein that has not yet been characterised. The following example serves to illustrate this: colorectal carcinoma patients overexpress CD55 and have significantly reduced 7-year survival (64). A human antiidiotypic antibody, which mimics CD55 (DAF), has shown success in vaccination trials involving patients with colorectal cancer and osteosarcoma (65). Tumour-expressed complement downregulators such as CD55 are thought to provide an advantage to survival and expansion of tumour cells by protecting them from complement-mediated attack. However, more recently, it has been shown that CD55 binds to CD97, thereby effecting mediation of intercellular adhesion. This binding appears to be related to the depth of invasion of gastric carcinoma (66). Further, CD55 synthesis is increased by prostaglandin E2 (67), a cyclooxygenase derived mediator, which favors tumour progression (68). Therefore, CD55 blockade is likely to target two functions of the membrane bound regulator; a function exerted with the host interface (complement downregulation) and another, defining malignancy of the tumour (invasiveness).

\section{Conclusions and outlook}

Complement modifies tumour growth, metastasis and responses to therapeutics. Complement is a player in the host interactions with neoplastic changes, which can be exploited therapeutically. Important factors with relevance to the success of this strategy deserve more attention; leukemic vs. solid tumour (fluid phase vs. stroma), environment (hypoxia), epithelial-mesenchymal transition and related surface changes.

Complement activation may, however, also complicate therapy regimes; a recent study concluded that nanoparticles, which are polyethyleneglycol-grafted liposomes entrapping cytostatica, may activate complement on their surface, leading to unwanted systemic side effects (69). The extent of macrophage-mediated crosstalk of complement activation with TLR signalling may be decisive in determining the efficacy of therapeutic targeting of complement; in a murine study of photodynamic therapy of squamous cell carcinoma, TLR-mediated signalling led to an increase in transcription of complement genes (70).

There is a clear need for further systematic studies to elucidate mechanisms of complement-mediated control of growth and metastasis of tumours differing in their immunogenicity. It is likely that tumours skew the type of immune responses (innate vs. adaptive), and success in therapeutically interfering with the innate and adaptive systems will depend on tumour immunogenicity. Mouse models ideally should cover all stages of tumour development; so far, only models of tumour escape have been investigated in complement-targeted mouse lines. Only one study has investigated prior stages in a transgenic model backcrossed to a $\mathrm{C} 3$ deficient background in which human keratin 14 promoter/enhancer controls the expression of early region genes of human papillomavirus type 16 , providing a multistage epithelial carcinogenesis model, and found no role for $\mathrm{C} 3$ in neoplastic progression (71). Adjustment of observation times may be crucial as a study investigating the expressed serum proteome in murine bronchioalveolar carcinoma implies: properdin for example is elevated only at the late stage (14 months) (72). The design of the study does not allow for a conclusion as to the functional importance of this elevation. Use of laser capture microdissection and microarray analysis enables characterisation of gene expression in stroma vs. tumour (73), and may aid in the discovery of new functionalities. CD55 e.g. is more expressed in stroma than in colorectal tumour (74).

Modulation of complement activation and regulation has been a strategic approach in drug development with varying success (75). A greater understanding of the relationship of complement and the environment of relevance to tumour (hypoxia, modifications, binding partners and networks, enzymatic activity) is needed. In the majority of studies, 
modulation of the complement system appears to act as an adjuvant to increase the efficiency of the primary treatment. This aspect will be elaborated hereafter.

The potential lies in combination therapy approaches. Promissing results, favoring an approach to interfere with more than one system involved in the anti-tumour response, have been achieved using mouse models (31). Anti-VEGF (bevacizumab) with B-glucan were effective in a mouse model of lung cancer (s.c. and orthotopic) (76), and antiEGFR (cetuximab) combined with $\beta$-glucan lead to significant regression non-small cell lung carcinoma (s.c.) and increase in survival in a mouse model (77). B-glucans function by priming tumour effector cells; $\beta$-glucans are taken up by macrophages, and $\beta$-glucan fragments are released in the reticuloendothelial system and taken up via CR3 by phagocytic cells, which are then more likely to uptake antibody labelled tumour cells (78). The significance of the tumoricidal effect of B-glucan has been shown in vitro (79) and in vivo (80). A triple treatment employing anti- CD55, Bglucan, and trastuzumab (anti-Her-2/neu Ab) has been efficacious in a mouse xenograft model of ovarian carcinoma (81), yielding a targeted and local overactivation of complement.

Greater, tumour-specific knowledge of expression of regulatory complement proteins and their relation of clinical progression is needed in order to tailor combinatorial therapies (82). Further avenues to explore are the usefulness of combining PEG-liposomes (used for administration of the cytostatic doxorubicin, as Doxil ${ }^{\circledR}$ ) with sCR1 or with C5aR antagonist (to block undesired, PEG-liposome-mediated, systemic complement activation, see ref. 69,83) and increasing the efficacy of IL-12 therapy of cancer (84) by co-administering C5aR blockade (to block C5a-mediated suppression of IL-12 by IFN $\gamma$ primed cells, see ref. 85).

By contrast, the results of a most recent study favour as therapeutic approach a blockade of complement activation because C5a blocking peptide PMX-53 was beneficial to the outcome in a non-orthotopic mouse model over a period of at least 34 days (86).

Is this approach really in complete contrast to the therapeutic downregulation of complement regulators? These have been most successfully used together with tumour-specific antibodies, whose efficacy is directly dependent on complement activation via the classical pathway (30). The net result of their functions will be a considerable increase of C5a, while lesser C5a amounts are needed to exert chemotactic functions. This differential integration of C5a levels has been suggested in the literature and a model discussed, by which the strength of exposure to $\mathrm{C} 5 \mathrm{a}$ and the presence of complement enhancers such as $\mathrm{C} 3 \mathrm{~b}$, iC $3 \mathrm{~b}$ modulate the immune response (87). It is conceivable that tumour cells growing in situ and those that hematogenously spread generate different levels of C5a by the mere compartment they are in. This may indeed be a factor in the opposing conclusions on the role of complement reached in the two seminal pieces of work investigating epithelial cancer in situ (20) and metastasising bladder cancer (17) in mice of the same genetic background. In fact, by design of the mouse models that demonstrate the relevance of downregulated CD55 or CD59 in decreasing tumour burden, these are metastatic either by route of administration of manipulated tumour cells (58) or by the time of observation (s.c., 6 weeks) (52). Thus, it appears that adjuvant support of C5a may hold promise in limiting metastasis, thereby providing a unifying hypothesis as to the reason for significantly less tumour burden in wildtype compared to $\mathrm{C} 3$ deficient mice in a metastasising melanoma model (57), while the blockade of C5a leads to a reduced tumour burden in neoplastic growth models. It is unclear at present to which extent the $\mathrm{C} 5 \mathrm{a}$ receptors, $\mathrm{C} 5 \mathrm{aR}$ and C5L2 (a decoy receptor of C5aR with anti-inflammatory properties; ref. 88) are involved in the mediation of these effects. While the affinities for C5a are comparable between C5aR and C5L2, C5L2 binds C5adesarg with greater affinity than C5aR (89). It is intriguing to speculate that the seemingly opposing role of complement in tumour growth and metastasis could be due to a skewing in triggering C5aR/C5L2. Clearly, more, systematically conducted, research is needed to arrive at a unifying concept and constructively inform the design of therapeutics that target complement.

\section{References}

1. Liszewski M, Fang $\mathrm{C}$ and Atkinson J: Inhibiting complement activation on cells at the step of C3 cleavage. Vaccine 26 (Suppl 8): 122-127, 2008.

2. Fearon D and Carroll M: Regulation of B lymphocyte responses to foreign and self-antigens by the CD19/CD21 complex. Annu Rev Immunol 18: 393-422, 2000

3. Kemper $\mathrm{C}$ and Atkinson J: T-cell regulation: with complements from innate immunity. Nat Rev Immunol 7: 9-18, 2007.

4. Longhi MP, Harris C, Morgan B and Gallimore A: Holding T cells in check - a new role for complement regulators? Trends in Immunol 27: 102-108, 2006.

5. Reis E, Barbuto J, Köhl J and Isaac L: Impaired dendritic cell differentiation and maturation in the absence of C3. Mol Immunol 45: 1952-1962, 2008.

6. Fernandez Gonzalez S, Jayasekera J and Carroll M: Complement and natural antibody are required in the long-term memory response to influenza virus. Vaccine 26 (Suppl 8): 186-193, 2008.

7. Huflejt M, Vuskovic M, Vasiliu D, Xu H, Obukhova P, Shilova N, Tuzikov A, Galanina O, Arun B, Lu K and Bovin N: Anticarbohydrate antibodies of normal sera: findings, surprises and challenges. Mol Immunol 46: 3037-3049, 2009.

8. Gancz D and Fishelson Z: Cancer resistance to complementdependent cytotoxiciy (CDC): Problem-oriented research and development. Mol Immunol 46: 2794-2800, 2009.

9. Kim D, Martin C, Lee S and Martin B: Expression of complement protein $\mathrm{C} 5 \mathrm{a}$ in a murine mammary cancer model: tumor regression by interference with the cell cycle. Cancer Immunol Immunother 54: 1026-1037, 2005.

10 Sjöberg A, Trouw L and Blom A: Complement activation and inhibition: a delicate balance. Trends Immunol 30: 83-90, 2008.

11. Cotter T: Apoptosis and cancer: the genesis of a research field. Nature Rev Cancer 9: 501-507, 2009.

12. Morgan J, Spendlove I and Durrant L: The role of CD55 in protecting the tumour environment from complement attack. Tissue Antigens 60: 213-223, 2002.

13. Mikesch J-H, Buerger H, Simon R and Brandt B: Decayaccelerating factor (CD55): A versatile acting molecule in human malignancies. Biochim Biophys Acta 1766: 42-52, 2006.

14. Kusama T, Miyagawa S, Moritan T, Kubo T, Yamada M, Sata H, Fukuta D, Matsunami K and Shirakura R: Downregulation of NK cell-mediated swine endothelial cell lysis by DAF (CD55). Transplant Proc 35: 529-530, 2003.

15. Liu J, Miwa T, Hilliard B, Chen Y, Lambris J, Wells A and Song W-C: The complement inhibitory protein DAF (CD55) suppresses T cell immunity in vivo. J Exp Med 201: 567-577, 2005.

16. Zhang X, Kimura Y, Fang C, Zhou L, Sfyroera G, Lambris JD, Wetsel RA, Miwa T and Song W-C: Regulation of Toll-like receptor-mediated inflammatory response by complement in vivo. Blood 110: 228-236, 2007. 
17. Varela J, Imai M, Atkinson C, Ohta R, Rapisardo M and Tomlinson S: Modulation of protective T cell immunity by complement inhibitor expression on tumor cells. Cancer Res 68: 6734- 6742, 2008

18. Kilgore K, Schmid E, Shanley T, Flory C, Maheswari V, Tramontini N, Cohen $\mathrm{H}$, Ward P, Friedl $\mathrm{H}$ and Warren J: Sublytic concentrations of the membrane attack complex of complement induce endothelial interleukin-8 and monocyte chemoattractant protein-1 through nuclear factor-kappa B activation. Am J Pathol 150: 2019-2031, 1997.

19. Reiter Y, Ciobotariu A and Fishelson Z: Sublytic complement attack protects tumor cells from lytic doses of antibody and complement. Eur J Immunol 22: 1207-1213, 1992.

20. Markiewski M, DeAngelis R, Benencia F, Ricklin-Lichtsteiner S, Koutoulaki A, Gerard C, Coukos G and Lambris J: Modulation of the antitumor immune response by complement. Nat Immunol 9: 1225-1235, 2008.

21. Orr F, Mokashi S and Delikatny J: Generation of a complementderived chemotactic factor for tumor cells in experimentally induced peritoneal exudates and its effect on the local metastasis of circulating tumor cells. Am J Pathol 108: 112-118, 1982

22. Dolcetti L, Marigo I, Mantelli B, Peranzoni E, Zanovello P and Bronte V: Myeloid-derived suppressor cell role in tumor-related inflammation. Cancer Lett 267: 216-225, 2008.

23. Lee HM, Wu W, Wysoczynski M, Liu R, Zuba-Surma EK, Kucia M, Ratajczak J and Ratajczak MZ: Impaired mobilization of hematopoietic stem/progenitor cells in C5-deficient mice supports the pivotal involvement of innate immunity in this process and reveals novel promobilization effects of granulocytes. Leukemia 23: 2052-2062, 2009.

24. Lalli P, Strainic M, Lin F, Medof M and Heeger P: Decay accelerating factor can control $\mathrm{T}$ cell differentiation into IFN- $\gamma$ producing effector cells via regulating local C5a-induced IL-12 production. J Immunol 179: 5793-5802, 2007

25. Kuraya M, Ming Z, Liu X, Matsushita M and Fujita T: Specific binding of $\mathrm{L}$-ficolin and $\mathrm{H}$-ficolin to apoptotic cells leads to complement activation. Immunobiology 209: 689-697, 2005.

26. Schwartz-Albiez R, Laban S, Eichmüller S and Kirschfink M: Cytotoxic natural antibodies against human tumours: An option for anti-cancer immunotherapy? Autoimmun Rev 7: 491-495, 2008.

27. Wasiuk A, de Vries V, Hartmann K, Roers A and Noelle R: Mast cells as regulators of adaptive immunity to tumours. Clin Exp Immunol 155: 140-146, 2008

28. Brandeis W, Tan C, Wang Y, Good R and Day N: Circulating immune complexes, complement and complement component levels in childhood Hodgkin's disease. Clin Exp Immunol 39: 551-561, 1980

29. Gropp C, Havemann K, Scherfe T and Ax W: Incidence of circulating immune complexes in patients with lung cancer and their effect on antibody-dependent cytotoxicity. Oncology 37 : $71-76,1980$

30. Di Gaetano N, Cittera E, Nota R, Vecchi A, Grieco V, Scanziani E, Botto M, Introna M and Golay J: Complement activation determines the therapeutic activity of rituximab in vivo. J Immunol 171: 1581-1587, 2003.

31. Macor P and Tedesco F: Complement as effector system in cancer immunotherapy. Immunol Lett 111: 6-13, 2007.

32. DeNardo DG and Coussens LM: Inflammation and breast cancer. Balancing immune response: crosstalk between adaptive and innate immune cells during breast cancer progression. Breast Cancer Res 9: 212-222, 2007.

33. Lin W-W and Karin M: A cytokine-mediated link between innate immunity, inflammation, and cancer. J Clin Invest 117 $1175-1183,2007$

34. Lucas S, Karlsson-Parra A, Nilsson B, Grimelius L, Åkerström G, Rastad J and Juhlin C: Tumor-specific depostion of immunoglobulin $\mathrm{G}$ and complement in papillary thyroid carcinoma. Hum Pathol 27: 1329-1335, 1996.

35. Ostrand-Rosenberg S and Sinha P: Myeloid-derived suppressor cells: linking inflammation and cancer. J Immunol 182: 4499-4506, 2009.

36. Marigo I, Dolcetti L, Serafini P, Zanovello P and Bronte V: Tumor-induced tolerance and immune suppression by myeloid derived suppressor cells. Immunol Rev 222: 162-179, 2008.

37. Johansson M, DeNardo D and Coussens L: Polarized immune responses differentially regulate cancer development. Immunol Rev 222: 145-154, 2008

38. Sikkeland LI, Thorgersen EB, Haug T and Mollnes TE: Complement activation and cytokine response by BioProtein, a bacterial single cell protein. Clin Exp Immunol 148: 146-152, 2007.
39. Tolsma SS, Volpert OV, Good DJ, Frazier WA, Polverini PJ and Bouck N: Peptides derived from two separate domains of the matrix protein thrombospondin-1 have anti-angiogenic activity. J Cell Biol 122: 497-511, 1993.

40. Prater C, Plotkin J, Jaye D and Frazier W: The properdin-like type I repeats of human thrombospondin contain a cell attachment site. J Cell Biol 112: 1031-1040, 1991.

41. Pattrick M, Luckett J, Yue L and Stover C: Dual role of complement in adipose tissue. Mol Immunol 46: 755-760, 2009.

42. Liu D, Shriver Z, Venkataraman G, El Shabrawi Y and Sasisekharan R: Tumor cell surface heparan sulfate as cryptic promoters or inhibitors of tumor growth and metastasis. Proc Natl Acad Sci USA 99: 568-573, 2002.

43. Kemper C, Mitchell L, Zhang L and Hourcade D: The complement protein properdin binds apoptotic $\mathrm{T}$ cells and promotes complement activation and phagocytosis. Proc Natl Acad Sci 105: 9023-9028, 2008.

44. Kuderer NM, Ortel TL and Francis CW: Impact of venous thromboembolism and anticoagulation on cancer and cancer survival. J Clin Oncol 27: 4902-4911, 2009.

45. Gerotziafas GT, Papageorgiou C, Hatmi M, Samama MM and Elalamy I: Clinical studies with anticoagulants to improve survival in cancer patients. Pathophysiol Haemost Thromb 36: 204-211, 2008

46. Almeda S, Rosenberg RD and Bing DH: The binding properties of human complement component $\mathrm{C} 1 \mathrm{q}$. Interaction with mucopolysaccharides. J Biol Chem 258: 785-791, 1983

47. Caldwell EE, Andreasen AM, Blietz MA, Serrahn JN, Van der Noot V, Park Y, Yu G, Linhardt RJ and Weiler JM: Heparin binding and augmentation of $\mathrm{C} 1$ inhibitor activity. Arch Biochem Biophys 361: 215-222, 1999.

48. Casu B, Vlodavsky I and Sanderson RD: Non-anticoagulant heparins and inhibition of cancer. Pathophysiol Haemost Thromb 36: 195-203, 2008.

49. Mousa SA, Linhardt R, Francis JL and Amirkhosravi A: Antimetastatic effect of a non-anticoagulant low-molecular-weight heparin versus the standard low-molecular-weight heparin, enoxaparin. Thromb Haemost 96: 816-821, 2006.

50. Irigoyen M, Ansó E, Martínez E, Garayoa M, Martínez-Irujo J and Rouzaut A: Hypoxia alters the adhesive properties of lymphatic endothelial cells. A transcriptional and functional study. Biochim Biophys Acta 177: 880-890, 2007

51. Okroj M, Corrales L, Stokowska A, Pio R and Blom A: Hypoxia increases susceptibility of non-small cell lung cancer cells to complement attack. Cancer Immunol Immunother 58: $1773-1782,2009$

52. Shi X, Zhang B, Zhang J, Wang G and Gao M: CD59 silencing via retrovirus-mediated RNA interference enhance complementmediated cell damage in ovary cancer. Cell Mol Immunol 6: 61-66, 2009

53. Zell S, Geis N, Rutz R, Schultz S, Giese T and Kirschfink M: Down-regulation of CD55 and CD46 expression by anti-sense phosphorothioate oligonucleotides (S-ODNs) sensitizes tumour cells to complement attack. Clin Exp Immunol 150: 576-584, 2007.

54. Saldova R, Wormald M, Dwek R and Rudd P: Glycosylation changes on serum glycoproteins in ovarian cancer may contribute to disease pathogenesis. Dis Markers 25: 219-232, 2008

55. Qiu Y, Patwa TH, Xu L, Shedden K, Misek DE, Tuck M, Jin G, Ruffin MT, Turgeon DK, Synal S, Bresalier R, Marcon N, Brenner DE and Lubman DM: Plasma glycoprotein profiling for colorectal cancer biomarker identification by lectin glycoarray and lectin blot. J Proteome Res 7: 1693-1703, 2008.

56. Frade R, Rodrigues-Lima F, Huang S, Xie K, Guillaume N and Bar-Eli M: Procathepsin-L, a proteinase that cleaves human C3 (the third component of complement), confers high tumorigenic and metastatic properties to human melanoma cells. Cancer Res 58: 2733-2736, 1998

57. Rozanov D, Savinov A, Golubkov V, Tomlinson S and Strongin A: Interference with the complement system by tumor cell membrane type-1 matrix metalloproteinase plays a significant role in promoting metastasis in mice. Cancer Res 66: 6258-6263, 2006

58. Loberg R, Day L, Dunn R, Kalikin L and Pienta K: Inhibition of Decay-accelerating factor (CD55) attenuates prostate cancer growth and survival in vivo. Neoplasia 8: 69-78, 2006.

59. Hawlisch H, Belkaid Y, Baelder R, Hildeman D, Gerard C and Köhl J: C5a negatively regulates toll-like receptor 4-induced immune responses. Immunity 22: 415-426, 2005. 
60. Zhou X, Hu W and Qin X: The role of complement in the mechanism of action of rituximab for B-cell lymphoma: implications for therapy. Oncologist 13: 954-966, 2008.

61. Korbelik M and Cecic I: Complement activation cascade and its regulation: relevance for the response of solid tumors to photodynamic therapy. J Photochem Photobiol B 93: 53-59, 2008.

62. Sivasankar B, Longhi MP, Gallagher K, Betts G, Morgan BP, Godkin A and Gallimoore A: CD59 blockade enhances antigenspecific $\mathrm{CD} 4{ }^{+} \mathrm{T}$ cell responses in humans: a new target for cancer immunotherapy. J Immunol 182: 5203-5207, 2009.

63. Yan J, Allendorf D, Li B, Yan R, Hansen R and Donev R: The role of membrane complement regulatory proteins in cancer immunotherapy. Adv Exp Med Biol 632: 159-174, 2008.

64. Durrant LG, Chapman MA, Buckley DJ, Spendlove I, Robins RA and Armitage NC: Enhanced expression of the complement regulatory protein CD55 predicts a poor prognosis in colorectal cancer patients. Cancer Immunol Immunother 52: 638-642, 2003.

65. Durrant L and Spendlove I: Immunization against tumor cell surface complement-regulatory proteins. Curr Opin Investig Drugs 2: 959-966, 2001

66. Liu Y, Chen L, Peng S, Chen Z, Gimm O, Finke R and Hoang$\mathrm{Vu} \mathrm{C}$ : The expression of CD97EGF and its ligand CD55 on marginal epithelium is related to higher stage and depth of tumor invasion of gastric carcinomas. Oncol Rep 14: 1413-1420, 2005.

67. Holla V, Wang D, Brown J, Mann J, Katkuri S and DuBois R: Prostaglandin E2 regulates the complement inhibitor CD55/ Decay-accelerating factor in colorectal cancer. J Biol Chem 280: 476-483, 2005 .

68. Greenhough A, Smartt H, Moore A, Roberts H, Williams A, Paraskeva $\mathrm{C}$ and Kaidi A: The COX-2/PGE 2 pathway: key roles in the hallmarks of cancer and adaptation to the tumour microenvironment. Carcinogenesis 30: 377-386, 2009.

69. Moghimi S and Andresen T: Complement-mediated tumour growth: Implications for cancer nanotechnology and nanomedicines. Mol Immunol 46: 1571-1572, 2009.

70. Korbelik M: Complement upregulation in photodynamic therapy-treated tumors: Role of Toll-like receptor pathway and NFkB. Cancer Lett 281: 232-238, 2009.

71. Visser K, Korets L and Coussens L: Early neoplastic progression is complement independent. Neoplasia 6: 1-9, 2004.

72. Chatterji B and Borlak J: A 2-DE MALDI-TOF study to identify disease regulated serum proteins in lung cancer of c-myc transgenic mice. Proteomics 9: 1044-1056, 2009.

73. Nambiar P, Boutin S, Raja R and Rosenberg D: Global gene expression profiling: a complement to conventional histopathologic analysis of neoplasia. Vet Pathol 42: 735-752, 2005.

74. Li L, Spendlove I, Morgan J and Durrant L: CD55 is overexpressed in the tumour environment. Br J Cancer 84: 80-86, 2001.

75. Ricklin D and Lambris J: Complement-targeted therapeutics. Nat Biotechnol 25: 1265-1275, 2007.
76. Zhong W, Hansen R, Li B, Cai Y, Salvador C, Moore G and Yan J: Effect of yeast-derived beta-glucan in conjunction with bevacizumab for the treatment of human lung adenocarcinoma in subcutaneous and orthotopic xenograft models. J Immunother 32: 703-712, 2009.

77. Li B, Allendorf DJ, Hansen R, Marroquin J, Cramer DE Harris CL and Yan J: Combined yeast (beta)-glucan and antitumor monoclonal antibody therapy requires C5a-mediated neutrophil chemotaxis via regulation of decay-accelerating factor CD55. Cancer Res 67: 7421-7430, 2007.

78. Chan G, Chan W and Sze D: The effects of B-glucan on human immune and cancer cells. J Hem Oncol 2: 25-35, 2009.

79. Xia Y, Vetvicka V, Yan J, Hanikyrova M, Mayadas T and Ross G: The B-glucan-binding lectin site of mouse CR3 $(\mathrm{CD} 11 \mathrm{~b} / \mathrm{CD} 18)$ and its function in generating a primed state of the receptor that mediates cytotoxic activation in response to iC3b-opsonized target cells. J Immunol 162: 2281-2290, 1999.

80. Hong F, Hansen R, Yan J, Allendorf D, Baran J, Ostroff G and Ross G: B-glucan functions as an adjuvant for monoclonal antibody immunotherapy by recruiting tumoricidal granulocytes as killer cells. Cancer Res 63: 9023-9031, 2003.

81. Liu J, Gunn L, Hansen R and Yan J: Combined yeast-derived B-glucan with anti-tumor monoclonal antibody for cancer immunotherapy. Exp Mol Pathol 86: 208-214, 2009.

82. Zhao W-P, Zhu B, Duan Y-Z and Chen Z-T: Neutralization of complement regulatory proteins CD55 and CD59 augments therapeutic effect of herceptin against lung carcinoma cells. Oncol Rep 21: 1405-1411, 2009.

83. Hamad I, Hunter AC, Szebeni J and Moghimi S: Poly(ethylene glycol)s generate complement activation products in human serum through increased alternative pathway turnover and a MASP-2-dependent process. Mol Immunol 46: 225-232, 2008.

84. Pavlin D, Cemazar M, Kamensek U, Tozon N, Pogacnik A and Sersa G: Local and systemic antitumor effect of intratumoral and peritumoral IL-12 electrogene therapy on murine sarcoma. Cancer Biol Ther 8: 1-9, 2009.

85. Wittmann M, Zwirner J, Larsson V-A, Kirchhoff K, Begemann G, Kapp A, Götze O and Werfel T: C5a suppresses the production of IL-12 by IFN- $\gamma$-primed and lipopolysaccharide-challenged human monocytes. J Immunol 162: 6763-6769, 1999.

86. Markiewski M and Lambris J: Unwelcome complement. Cancer Res 69: 6367-6370, 2009.

87. Karp C and Wills-Karp M: Complement and IL-12: yin and yang. Microbes Infect 3: 109-119, 2001.

88. Gerard N, Lu B, Liu P, Craig S, Fujiwara Y, Okinaga S and Gerard C: An anti-inflammatory function for the complement anaphylatoxin C5a-binding protein. J Biol Chem 280: 39677-39680, 2005

89. Scola A, Higginbottom A, Partridge L, Reid R, Woodruff T, Taylor S, Fairlie D and Monk P: The role of the N-terminal domain of the complement fragment receptor C5L2 in ligand binding. J Biol Chem 282: 3664-3671, 2007. 